\title{
Matching the BRIC equity premium: A structural approach
}

\section{Giuliano Curatola, Michael Donadelli*, Patrick Grüning}

Research Center SAFE (House of Finance), Goethe University Frankfurt, Germany

\section{A R T I C L E I N F O}

\section{Article history:}

Received 11 March 2014

Received in revised form 4 December 2014

Accepted 18 December 2014

Available online 26 December 2014

JEL classification:

G12

G15

Keywords:

BRIC countries

Equity risk premium

Long-run risk

Persistence

\begin{abstract}
A B S T R A C T
The equity risk premium (ERP) in BRIC markets is, on average, significantly higher than that in the US market. This paper employs an endowment economy with recursive preferences and long-run risk to explain the ERP generated by a portfolio of BRIC equity indices. The combination of recursive preferences and long-run risk partially explains the BRIC ERP. It turns out that there is a puzzle with respect to BRIC data as well. This holds even if we account for high levels of aversion to consumption and utility risk and for the empirically observed autoregressive structure of US consumption and BRIC dividend growth.
\end{abstract}

(c) 2014 Elsevier B.V. All rights reserved.

\section{Introduction}

The equity premium puzzle, originally posed by Mehra and Prescott (1985), refers to the empirical fact that, over the last century, US stocks have paid an average return in excess of a relatively risk-less security of about $6 \%$. Since then, an increasing body of literature has been devoted to the search for an explanation of this puzzle. Several remarkable theories have been proposed to explain the equity risk premium (ERP) of US stocks: the behavioral finance explanation suggested by Benartzi and Thaler (1995), the habit formation approach of Campbell and Cochrane (1999), and, more recently, the long-run risk model of Bansal and Yaron (2004).

However, the ERP is not unique to US capital markets. Recent studies find that the ERP in emerging markets exceeds that in the US by a margin of about 20\% (see Grootveld and Salomons (2003); Mehra (2006);

\footnotetext{
* Corresponding author at: Research Center SAFE, Goethe University Frankfurt, Grüneburgplatz 1, 60323 Frankfurt am Main, Germany. Tel.: + 4969798 33882; fax: + 496979830077 .

E-mail addresses: curatola@safe.uni-frankfurt.de (G. Curatola), michael.donadelli@gmail.com (M. Donadelli), gruening@safe.uni-frankfurt.de (P. Grüning)
} 
Shackman (2006); Donadelli and Prosperi (2012), among others). This "compensation gap" increased in the aftermath of the emerging systemic banking crisis of the late '90s, as reported by Donadelli and Persha (2014). These findings are intriguing, from both theoretical and empirical points of view. It is unquestionable that, as a result of globalization, investors today have more opportunities to diversify their portfolios internationally than in the recent past. For instance, many exchange-traded funds track equity indexes of BRIC economies and are traded in the major stock exchanges worldwide, including the US. In addition, Edison and Warnock (2004) provide compelling evidence that holdings of emerging market equity by US investors are indeed large and economically significant. A natural research question is then the following: why is the ERP in emerging markets so different from the one in the US? Admittedly, there is more cash-flow risk in investing in BRIC economies than in the US. But are these differences enough to justify a premium of emerging markets over the US market of about 20\% (or more)? In summary, we still lack a theoretical model that links the cash-flow of emerging market equity to expected returns and rationalizes the differences in the ERP across different countries.

In this paper, we provide updated empirical evidence on the ERP of BRIC countries. Then, we take the point of view of a US\$-based investor who allocates wealth either to the US equity market or to a composite portfolio of BRIC equity indices. The case of a portfolio composed of both the US equity index and the BRIC portfolio is also considered. We assume that the investor has Epstein and Zin (1989) preferences and that consumption and dividend dynamics incorporate long-run risk in the spirit of Bansal and Yaron (2004). First, we examine whether the benchmark model of Bansal and Yaron (2004), calibrated to match US consumption data over the period 1988:1Q-2008:2Q, is able to match the BRIC ERP. We document that the model produces a relatively low ERP and return volatility, inconsistently with BRIC equity market data. This holds even if we set the relative risk aversion (RRA) and the elasticity of intertemporal substitution (EIS) to unrealistically large values. Second, in the spirit of Pancrazi (2014) and Pancrazi and Vukotic (2013), we characterize the US consumption and the US and BRIC dividend growth dynamics as third order autoregressive processes. By accounting for the rich autoregressive structure of US consumption and US dividend growth, the model matches the US ERP even with a moderate level of risk aversion. Of course, it produces a higher equity market return volatility but also a higher Sharpe ratio than in the benchmark case. However, it is still slightly below the value found in US asset pricing data. Differently, the weaker autoregressive structure of BRIC dividends gives rise to a relatively low ERP (inconsistent with both US and BRIC asset pricing data). Thus, the ERP remains extremely far from its empirical counterpart. These results suggest that future research should explore in more details the links between investors' preferences and ERP of emerging markets.

Our paper is related to the emerging literature that proposes a structural approach to explain the returns of emerging economies. An early attempt to match the ERP in emerging market via a consumption-based model is undertaken in Mehra (2006). In particular, he focuses on the ERP generated by the Indian equity market over the period 1991-2004. Using a model as in Mehra and Prescott (1985), he observes that the ERP is in the range of $0.02 \%$ to $0.16 \%$ (if the coefficient of risk aversion is assumed to vary from 2 to 10). However, Indian data suggest an ERP value above $11 \% .{ }^{1}$ He concludes that there is a puzzle associated to Indian data as well. More recently, Jahan-Parvar et al. (2013) build a production economy to match business cycle moments and equity returns of Argentina, Brazil, and Chile. To explain the ERP associated to Latin American asset pricing data they add to a standard real business cycle model: i) borrowing and lending costs; ii) capital adjustment cost; iii) GHH rather than CRRA preferences; iv) frictions on working capital. In this way, they make the marginal rate of substitution between consumption today and consumption tomorrow and the equity returns more volatile and improve consumption smoothing. Overall, the theoretical literature on equity premia in emerging markets is rather thin. With this work, we aim to fill part of this gap.

The remainder of this paper is organized as follows. Section 2 describes the data and provides the relevant empirical evidence. Section 3 develops the theoretical framework aimed at explaining the BRIC ERP. In Section 4, we present our benchmark calibration and discuss the relevant results. Section 5 concludes.

\footnotetext{
${ }^{1}$ Note that the analyzed sample does not include a period of increasing international equity market performances (i.e. 2005-2007). Accounting for this period, the ERP rises above $15 \%$.
} 


\section{Stylized facts: the BRIC economies and the ERP}

This study employs country equity indices for four emerging countries, namely, Brazil, China, India, and Russia (BRIC), ${ }^{2}$ and for comparison purposes, the US equity index. All equity indices are represented by US\$ Morgan Stanley Capital International (MSCI) Total Return Indices (TRI). Note that our indices include reinvested dividends, retain only US inflation, and alleviate exchange rate noise. ${ }^{3}$ Data are quarterly and run from 1988:1Q (or later) to 2008:2Q. ${ }^{4}$ To capture equity market performances across BRIC economies, we construct an equally weighted portfolio. Formally,

$$
B R I C_{p, t}=\omega_{i, t} \times M S C I T R I_{i, t}
$$

where $\omega_{i, t}=\frac{1}{N}$ and $N=4$. Since returns of BRIC indices are measured in US\$, we compute the ERP as the returns of BRIC indices in excess of the US risk-free rate. Formally,

$$
E R P_{p, t}=R_{p, t}-R_{f, t}
$$

where $R_{p, t}=\left[\left(B R I C_{p, t} / B R I C_{p, t}-1\right)-1\right]$ and $R_{f, t}$ represents the return of a riskless security (measured as the return of 3-month Treasury bills). Similarly, the US ERP is defined as follows, ERP $P_{U S, t}=\left(\begin{array}{ll}M S C I & T R R_{t}^{U S} \\ M S C I & T R I_{t-1}^{T S}\end{array}\right)-$ $R_{f, t}$. Note that all nominal quantities are deflated using the CPI. Our setup implies the following: i) a US\$based investor can invest only in an equally-weighted portfolio composed of BRIC countries' equity indices, or, alternatively, in the US equity market; ${ }^{5}$ ii) the BRIC portfolio is rebalanced on a quarterly basis; ${ }^{6}$ iii) the portfolios' performances retain only US inflation. ${ }^{7}$ Summary statistics for the BRIC and US ERP are reported in Table 1. The main statistical features are as follows. First, consistently with existing empirical findings (Donadelli, 2013; Donadelli and Paradiso, 2014; Grootveld and Salomons, 2003; Jahan-Parvar et al., 2013), we find that the ERP in emerging markets is significantly higher and much more volatile than that in the US market. ${ }^{8}$ Still, the BRIC Sharpe ratio is almost twice as large as the US one. Second, and not surprisingly, the US ERP displays negative skewness and a relatively low volatility (see also Bekaert et al. (1998); Grootveld and Salomons (2003); Donadelli (2013)). ${ }^{9}$

\footnotetext{
${ }^{2}$ According to the International Finance Corporation (1999), BRIC economies display i) low or middle income and ii) a low investable market capitalization/GDP ratio. We stress that, Brazil, Russia, India, and China account for almost $67 \%$ of the total market capitalization of the low \& middle income countries as well as for 46\% of the emerging and developing economies's GDP over the period 2000-2013. Source: IMF and World Economic Indicators.

3 These conversions represent a ubiquitous practice in empirical studies of international financial markets (see, for example, Grootveld and Salomons (2003); Pukthuanthong and Roll (2009); Donadelli and Paradiso (2014); among many others). With these conversions, one does not have to account for additional noise stemming from different inflation rates across the countries or exchange rate movements.

${ }^{4}$ Note that we exclude the financial crisis and European Sovereign debt crisis from our sample to avoid that the results are driven by this extraordinary period.

${ }^{5}$ In Section 4.3 below, we also consider the case of a US investor who invests in a mixed portfolio composed of the US equity index and the BRIC portfolio.

${ }^{6}$ Note that MSCI data for BRIC markets do not start simultaneously in 1987:4Q. Therefore, as data became available, new countries are added to our BRIC portfolio. Starting dates: Brazil (1987:4Q); Russia (1994:4Q); India (1992:4Q); China (1992:4Q).

${ }^{7}$ Measured in local currencies would be the purest form of the equity risk premium. However, in our opinion, it would be less interesting from the perspective of a US\$-based investor who is interested in investing exclusively in emerging/developing countries, because of the decline of the US ERP (Jagannathan et al., 2000; Lettau et al., 2006).

${ }^{8}$ In a local currency framework, Mehra (2006) finds that the ERP in the Indian market is around 12\% over the period 1991-2004. Similarly, Donadelli and Prosperi (2012) observe an ERP of 15\% across BRIC markets over the period 2000-2011. They also find that the ERP (in local currency) in Korea, Mexico and Turkey is higher than the ERP in the US (i.e. 9.6\%, $12.72 \%$ and $10.2 \%$ vs. $-1.8 \%$ ). Note that their sample includes the recent subprime crisis. Therefore, abstracting from the crisis, the ERP is even higher. Shackman (2006) measures the ERP in the US and in emerging markets both in local currency and US\$. He finds an ERP (in local currency) equal to $7.28 \%$ and $10.66 \%$, respectively, in the US and in the emerging markets. However, his sample does not include the post-emerging crises period. Jahan-Parvar et al. (2013) estimate the equity premium in Argentina, Brazil and Chile. They observe that "the annualized equity premia in US dollar terms in Argentina between 1993 and 2007 and in Brazil between 1991 and 2007 are, respectively, 12.72\% and $19.68 \%$ over the US 3-month Treasury bill rate".

9 "GDP-" and "Market Capitalization"-weighted portfolios give rise to similar statistics. Results are available upon request.
} 
Table 1

Summary statistics.

\begin{tabular}{lrrrr}
\hline \multirow{2}{*}{ ERP } & \multicolumn{2}{l}{ BRIC } & & US \\
\cline { 2 - 3 } \cline { 5 - 5 } & (Real) & (Nominal) & (Real) & (Nominal) \\
\hline Mean & 23.02 & 26.08 & 4.17 & 7.23 \\
StDev & 46.94 & 46.79 & 14.65 & 14.45 \\
ShR & 0.49 & 0.56 & 0.28 & 0.50 \\
Skew & 0.08 & 0.10 & -0.32 & -0.37 \\
Kurt & 0.67 & 0.66 & 0.89 & 0.91 \\
\hline
\end{tabular}

Notes: This table reports the values of the mean, standard deviation, Sharpe ratio, skewness, and kurtosis for the BRIC and US ERP. The 'Consumer Price Index for All Urban Consumers: All Items', which captures US inflation (source: U.S. Department of Labor: Bureau of Labor Statistics), is used to compute real quantities. Mean and standard deviation values are annualized and expressed in percentage points. All equity returns are computed from US\$-based MSCI TRIs. Data are quarterly and run from 1988:1Q to 2008:2Q.

\section{A framework to match the BRIC ERP}

Our structural approach relies on the asset pricing model with risks for the long-run proposed by Bansal and Yaron (2004). The choice of employing this model is motivated by two main factors: $\mathrm{i}$ ) it allows to account for changes in the dynamics of both consumption and dividend growth; and ii) because of the combination of recursive preferences and long-run risk, it is one of the few consumption-based asset pricing models that produces a relatively high ERP and relatively low risk-free rate (consistent with asset pricing data). In this work, we consider three departures from the baseline model of Bansal and Yaron (2004). First, we abstract from stochastic volatility (i.e. we do not account for fluctuating economic uncertainty). Second, we impose a realistic RRA value (i.e. we set RRA $=5$ ) for our benchmark economy (as suggested by Mehra and Prescott, 2008). ${ }^{10}$ Last, we characterize the exogenous dynamics of US consumption and US and BRIC dividend growth with an AR(3) process (see Section 4), consistent with existing empirical findings and the estimation results reported in this appendix.

\subsection{An endowment economy}

The representative agent has Epstein and Zin (1989) preferences. Formally,

$$
U_{t}=\left[(1-\delta)\left(C_{t}\right)^{\frac{1-\gamma}{\theta}}+\delta E_{t}\left[U_{t+1}^{1-\gamma}\right]^{\frac{1}{\theta}}\right]^{\frac{\theta}{1-\gamma}},
$$

where $0<\delta<1$ is the subjective discount factor, $\gamma$ is the coefficient of relative risk aversion, $\psi$ is the elasticity of intertemporal substitution, and $\theta=\frac{1-\gamma}{1-1 / \psi}$. In this environment, agents have preferences for early resolution of uncertainty, consistent with recent experimental studies (Brown and Kim, 2014). If $\gamma=1 / \psi$, preferences collapse to the standard power utility case. The representative agent's wealth evolves according to

$$
A_{t+1}=\left(A_{t}-C_{t}\right) R_{c, t+1}
$$

where $A_{t}$ is the agent's wealth and $R_{c, t}$ is the return on wealth. In this setup, the first order condition (FOC) for an asset that pays aggregate consumption takes the following form

$$
v_{c, t}=E_{t}\left[\delta^{\theta} e^{\left[-\frac{\theta}{\psi} \Delta c_{t+1}+(\theta-1) r_{c, t+1}\right]}\left(1+v_{c, t+1}\right) e^{\Delta c_{t+1}}\right]
$$

where $\Delta c_{t}$ is the exogenous consumption process, $r_{c, t+1}$ is the log of the gross return of consumption, and $v_{c, t}$ is the price-consumption ratio. Formally,

$$
\Delta c_{t+1}=\log \left(C_{t+1} / C_{t}\right) ; \quad r_{c, t+1}=\frac{\left(1+v_{c, t+1}\right) e^{\Delta c_{t+1}}}{v_{c, t}} ; \quad r_{c, t+1}=\log \left(R_{c, t+1}\right) ; \quad v_{c, t}=\frac{P_{c, t}}{C_{t}}
$$

\footnotetext{
${ }^{10}$ They write "most studies indicate a value for $\gamma$ that is close to 3". (p. 20).
} 
Similarly, the FOC for an asset that pays dividend $D_{t}$ in each period $t$ implies

$$
v_{d, t}=E_{t}\left[\delta^{\theta} e^{\left[-\frac{\theta}{\psi} \Delta c_{t+1}+(\theta-1) r_{c, t+1}\right]}\left(1+v_{d, t+1}\right) e^{\Delta d_{t+1}}\right]
$$

where $\Delta d_{t}$ is the growth rate of dividends and $v_{d, t}$ is the price-dividend ratio. Formally,

$$
\Delta d_{t+1}=\log \left(D_{t+1} / D_{t}\right) ; \quad v_{d, t}=\frac{P_{d, t}}{D_{t}} .
$$

Therefore, any asset can be priced via the following asset pricing equation

$$
1=E_{t}\left[\exp \left(m_{t+1}+r_{i, t+1}\right)\right]
$$

where $m_{t+1}$ is the $\log$ stochastic discount factor and $r_{i, t+1}$ is the $\log$ of the gross return on asset $i$. In this environment, $m_{t+1}$ takes the following form

$$
m_{t+1}=\theta \log (\delta)-\frac{\theta}{\psi} \Delta c_{t+1}+(\theta-1) r_{c, t+1} .
$$

Finally, following Bansal and Yaron (2004), consumption and dividend growth rates are characterized by the following exogenous processes

$$
\begin{aligned}
\Delta c_{t+1} & =\mu+x_{t}+\sigma_{c} \xi_{c, t+1} \\
\Delta d_{t+1} & =\mu+\lambda_{d} x_{t}+\phi_{d} \sigma_{c} \xi_{d, t+1} \\
x_{t+1} & =\rho_{x} x_{t}+\phi_{x} \sigma_{c} \xi_{x, t+1}
\end{aligned}
$$

where the shocks $\xi_{c, t+1}, \xi_{d, t+1}, \xi_{x, t+1}$ are i.i.d. normally distributed with mean zero and variance one, $x_{t}$ represents the long-run risk component of the consumption and dividend growth processes, and $\lambda_{d}$ is a parameter capturing the levered nature of dividends.

\subsection{Benchmark calibration}

The benchmark model employed in this paper requires us to specify nine parameters: three for preferences (i.e. $\delta, \psi$ and $\gamma$ ), four relating to the laws of motion of consumption and dividends (i.e. $\mu, \lambda_{d}, \phi_{d}$ and $\sigma_{c}$ ), and two for the long-run risk component (i.e. $\rho_{x}, \phi_{x}$ ). Since both asset prices and macro quantities are affected by this set of parameters, finding a proper calibration may be challenging. Table 2 summarizes our parameter choices. Both the subjective discount factor, $\delta$, and the intertemporal elasticity of substitution $\psi$ are calibrated as in the long-run risk literature. Specifically, as suggested by Bansal and Yaron (2004), we fix $\psi=1.5$. The last preference parameter is $\gamma$. Differently from recent long-run risk studies, which employ a value for $\gamma$ between 10 and 12, we choose $\gamma=5$. We stress that this value is in line with early works suggesting that the coefficient of relative risk aversion should be far below 10 (see Mehra and Prescott (1985, 2008)). The intercept, $\mu$, reflects the average of the US consumption growth estimated over the period 1988:1Q-2008:2Q. The two parameters characterizing the long-run component (i.e. $\rho_{x}$ and $\phi_{x}$ ) and the remaining parameters for the joint process of consumption and dividend growth (i.e. $\lambda_{d}, \phi_{d}$ and $\sigma_{c}$ ) are set to standard values used in the long-run risk literature and to achieve a relatively low consumption growth volatility, broadly consistent with the aforementioned period (i.e. the Great Moderation era from 1988:1Q to 2008:2Q). To this end, we fix $\sigma_{c}=0.00435$, which is three times lower than in Bansal and Yaron (2004).

The main message of this analysis is the following: given that our calibration relies on low risk aversion and aims to reproduce the low observed volatility of consumption growth we are not able to reproduce the US ERP in a realistic way. We will see in the next section that accounting for the observed persistence of consumption and dividends allows the model to explain the ERP of the US market while the ERP of BRIC markets can only be partially explained. 
Table 2

Benchmark calibration.

\begin{tabular}{lllllllll}
\hline$\delta$ & $\gamma$ & $\psi$ & $\mu$ & $\rho_{x}$ & $\lambda_{d}$ & $\sigma_{c}$ & $\phi_{x}$ & $\phi_{d}$ \\
\hline .9945 & 5 & 1.5 & 0.00514 & 0.98 & 3 & 0.00435 & 0.1 & 4.5 \\
\hline
\end{tabular}

Notes: This table reports the parameter values employed in our benchmark calibration. The model is calibrated at quarterly frequency.

\section{Matching the BRIC ERP}

\subsection{Re-examining the role of $\gamma, \psi$ and $\rho_{x}$}

In Table 3, we report the first and second moments of asset prices along with the mean and standard deviation of consumption growth generated by the model described in Section 3. Specification (1) reports results under our benchmark calibration (Table 2). Our benchmark calibration relies on low risk aversion and low consumption volatility and thus is not able to replicate the ERP of the US market. Asset pricing puzzles are even more severe in case of standard CRRA utility: the model produces an unrealistically high riskfree rate $(12.43 \%)$ and an unrealistically low ERP $(-0.19 \%)$. Columns (3)-(6) report the moments of asset prices for different values of $\gamma, \psi$ and $\rho_{x}$. As largely discussed in the long-run risk literature, higher RRA and EIS values tend to produce higher ERP (and higher Sharpe ratios). Note also that the ERP increases as the persistence parameter increases. ${ }^{11}$ Still, to have a sizable ERP $(2.72 \%)$ a higher level or risk aversion is needed (i.e. $\gamma=7.5$ ).

\subsection{The role of persistence in consumption and dividends}

Recent empirical findings have observed an increased persistence in macroeconomic variables (i.e. consumption, output, investment, and total factor productivity) as well as in dividends over the last 30 years (see Pancrazi (2014); Pancrazi and Vukotic (2013)). Based on this empirical evidence, we estimate the autoregressive parameters of the consumption process and dividend process over the period 1988:1Q2008:2Q. We use BEA data on real per-capita consumption growth of non-durables and services and Robert Shiller's dividend data to capture the US consumption and dividend growth rates, respectively. BRIC dividends are measured as the difference between $M S C I(T R I)$ and $M S C I(P I) .{ }^{12}$ Estimation results are reported in Table B. 1 in the appendix and suggest that: $\mathrm{i}$ ) the US consumption and dividend growth are characterized by a nonnegligible autoregressive structure $;^{13}$ ii) the autoregressive structure of BRIC dividends is relatively weak. ${ }^{14}$ As will become clear later, the lack of persistence in the dividend process of BRIC indices is the key to understand the inability of the long-run risk model to explain the ERP of BRIC markets.

Based on these empirical findings, we re-model consumption and dividend growth as follows

$$
\begin{aligned}
& \Delta c_{t+1}=\mu^{*}+\hat{\theta}_{c, 1} \Delta c_{t}+\hat{\theta}_{c, 2} \Delta c_{t-1}+\hat{\theta}_{c, 3} \Delta c_{t-2}+x_{t}+\sigma_{c} \xi_{c, t+1} \\
& \Delta d_{t+1}^{U S}=\mu^{*}+\hat{\theta}_{d, 1}^{U S} \Delta d_{t}^{U S}+\hat{\theta}_{d, 2}^{U S} \Delta d_{t-1}^{U S}+\hat{\theta}_{d, 3}^{U S} \Delta d_{t-2}^{U S}+\lambda_{d} x_{t}+\phi_{d} \sigma_{c} \xi_{d, t+1}^{U S} \\
& \Delta d_{t+1}^{B R I C}=\mu^{*}+\hat{\theta}_{d, 1}^{B R I C} \Delta d_{t}^{B R I C}+\hat{\theta}_{d, 2}^{B R I C} \Delta d_{t-1}^{B R I C}+\hat{\theta}_{d, 3}^{B R I C} \Delta d_{t-2}^{B R I C}+\lambda_{d} x_{t}+\phi_{d} \sigma_{c} \xi_{d, t+1}^{B R I C} \\
& x_{t+1}=\rho_{x} x_{t}+\phi_{x} \sigma_{c} \xi_{x, t+1}
\end{aligned}
$$

where $\left[\hat{\theta}_{c, 1} ; \hat{\theta}_{c, 2} ; \hat{\theta}_{c, 3}\right]$ are the estimated $\operatorname{AR}(3)$ parameters of US consumption growth, $\left[\hat{\theta}_{d, 1}^{U S}, \hat{\theta}_{d, 2}^{U S}, \hat{\theta}_{d, 3}^{U S}\right]$ and $\left[\hat{\theta}_{d, 1}^{B R I C}, \hat{\theta}_{d, 2}^{B R I C}, \hat{\theta}_{d, 3}^{B R I C}\right]$ are the estimated AR(3) parameters of the US and BRIC dividend growth process, respectively. Finally, we set $\mu^{*}=\mu\left(1-\hat{\theta}_{c, 1}-\hat{\theta}_{c, 2}-\hat{\theta}_{c, 3}\right)$. The quantitative implications of this autoregressive structure

\footnotetext{
${ }^{11}$ Note that $\rho_{x}$ moves from 0.98 to 0.985 . This is a small adjustment which does not affect the empirical properties of consumption growth. Anyhow, this value is in line with recent long-run risk studies.

12 PI denotes the price index that does not-in contrast to the total return index TRI-include reinvested dividends.

13 Note that, if US dividends are computed as the difference between the US MSCI TRI and the US MSCI PI, similar results are obtained.

14 It is important to note that the AR(1) parameter of the growth rate of the BRIC aggregate index is negative and statistically significant, whereas the same parameter is the US is positive and significant. In our opinion, this should be attributed to the presence of a relatively high instability in the dynamics of BRIC dividend growth rates (see Fig. A.1).
} 
Table 3

Model versus data: Asset prices.

\begin{tabular}{|c|c|c|c|c|c|c|c|c|c|}
\hline Model & $\begin{array}{l}(1) \\
B C\end{array}$ & $\begin{array}{l}(2) \\
C R R A \\
(\psi=0.2)\end{array}$ & $\begin{array}{l}(3) \\
\gamma=7.5\end{array}$ & $\begin{array}{l}(4) \\
\gamma=7.5 \\
\psi=2\end{array}$ & $\begin{array}{l}(5) \\
\rho_{x}=0.985\end{array}$ & $\begin{array}{l}(6) \\
\gamma=7.5 \\
\rho_{x}=0.985\end{array}$ & $\begin{array}{l}(7) \\
{\left[\hat{\theta}_{c, 1} ; \hat{\theta}_{c, 2} ; \hat{\theta}_{c, 3}\right]} \\
{\left[\hat{\theta}_{d, 1}^{U S}, \hat{\theta}_{d, 2}^{U S}, \hat{\theta}_{d, 3}^{U S}\right]}\end{array}$ & $\begin{array}{l}(8) \\
{\left[\hat{\theta}_{c, 1} ; \hat{\theta}_{c, 2} ; \hat{\theta}_{c, 3}\right]} \\
{\left[\hat{\theta}_{d, 1}^{B R I C}, \hat{\theta}_{d, 2}^{B R I C}, \hat{\theta}_{d, 3}^{B R I C}\right]}\end{array}$ & $\begin{array}{l}\text { Data } \\
\text { US (BRIC) }\end{array}$ \\
\hline$E\left(R^{m}-R_{f}\right)$ & 0.88 & -0.19 & 1.66 & 1.96 & 1.47 & 2.72 & 4.16 & 1.02 & $4.17(\mathbf{2 3 . 0 2})$ \\
\hline$\sigma\left(R^{m}\right)$ & 9.42 & 5.81 & 9.42 & 10.29 & 11.53 & 11.53 & 19.73 & 4.94 & $14.65(\mathbf{4 6 . 9 4 )}$ \\
\hline $\operatorname{ShR}$ & 0.09 & -0.04 & 0.18 & 0.19 & 0.13 & 0.24 & 0.21 & 0.21 & $0.28(\mathbf{0 . 4 9})$ \\
\hline$E\left(R_{f}\right)$ & 3.46 & 12.43 & 3.39 & 2.95 & 3.40 & 3.30 & 3.04 & 3.04 & 1.31 \\
\hline$\sigma\left(R_{f}\right)$ & 0.29 & 2.16 & 0.29 & 0.22 & 0.33 & 0.33 & 0.67 & 0.67 & 0.96 \\
\hline$E(\Delta c)$ & 2.06 & 2.06 & 2.06 & 2.06 & 2.06 & 2.06 & 2.06 & 2.06 & 2.06 \\
\hline$\sigma(\Delta c)$ & 0.97 & 0.97 & 0.97 & 0.97 & 1.00 & 1.00 & 1.32 & 1.32 & 0.36 \\
\hline
\end{tabular}

Notes: This table reports the annualized equity risk premium, $E\left(R^{m}-R_{f}\right)$ and mean risk-free rate, $E\left(R_{f}\right)$, the Sharpe ratio, ShR, and the annualized volatilities of the market return, $\sigma\left(R^{m}\right)$, and the risk-free rate, $\sigma\left(R_{f}\right)$. The last two lines report the average consumption growth, $E(\Delta c)$, and the volatility of consumption growth, $\sigma(\Delta c)$. All entries are obtained from repetitions of small-sample simulations. Bold values in parentheses report BRIC ERP statistics. $\left[\hat{\theta}_{c, 1} ; \hat{\theta}_{c, 2} ; \hat{\theta}_{c, 3}\right]$ and $\left[\hat{\theta}_{d, 1}^{i}, \hat{\theta}_{d, 2}^{i}, \hat{\theta}_{d, 3}^{i}\right]$ are estimated via the empirical scheme reported in the appendix (see entries in Table B.1). Data are quarterly and run from 1988:1Q to 2008:2Q.

are reported in columns (7) and (8) of Table $3 .{ }^{15}$ The main results are as follows. First, because of the delay in the resolution of uncertainty generated by the rich autoregressive structure of the US consumption and dividend growth, the model matches the US ERP. However, it also produces a market return volatility slightly larger than what has been observed in the data. Second, the relatively poor autoregressive structure of BRIC dividends does not allow the model to match the observed ERP and return volatility of BRIC markets: the ERP is $1.2 \%$ and the return volatility $4.94 \%$ which are both quite low values if compared to the observed ERP of $23 \%$ and return volatility of about $47 \% .{ }^{16}$ These results suggest that the equity premium puzzle is still particularly severe for emerging markets.

\subsection{An additional exercise}

In this section, we assume that our US\$-based investor invests in a mixed portfolio (hereinafter BRICUS), which is composed of the US equity index and the BRIC portfolio. We rely on three BRICUS portfolios: 1) 50\% US + 50\% BRIC; 2) $60 \%$ US + 40\% BRIC; and 3) $75 \%$ US + 25\% BRIC. ${ }^{17}$ Summary statistics for the ERP of these three portfolios are reported in Table 4.

We construct our BRICUS aggregate dividend indices following the aforementioned portfolio compositions. We then estimate the autoregressive parameters of these three new dividend processes via the empirical scheme described in the appendix. Estimation results are reported in Table B.2, and confirm that US and BRIC dividends have different autoregressive structures. The entries in Table B.2 are employed to re-model the dividend process reported in Eq. (B.1). ${ }^{18}$ From Table 5, we observe that the model produces a Sharpe ratio of the three BRICUS portfolios which is less than half of the observed ones.

Naturally, this problem is partially mitigated when we increase the degree of home bias. In fact, when we increase the fraction of US equity in the investor's portfolios, the target moments decrease and, at the same time, the degree of persistence of the BRICUS portfolio increases. This two effects together improve the ability

\footnotetext{
${ }^{15}$ Note that we only use the point estimates up to the highest significant lag. Hence, all three estimated parameters for consumption growth and only the first respective estimate for US and BRIC dividend growth are used in the calibration of the model.

${ }^{16}$ Under the benchmark calibration, $\gamma=75$ is needed to match the BRICERP. However, with $\gamma=17$ the model matches the BRIC Sharpe ratio.

${ }^{17}$ Note that in 2 out of 3 portfolios there is preference towards domestic stocks (i.e. home bias in equity). This is in line with existing studies (see Baele et al. (2007); Sorensen et al. (2007); Tretvoll (2008); Diyarbakirlioglu (2011); among many others).

${ }_{18}$ As before, we only use the point estimates up to the highest significant lag. Hence, all three estimated parameters for BRICUS (3) and only the first respective estimate for the other two portfolios are used in the calibration of the model.
} 
Table 4

Summary statistics.

\begin{tabular}{|c|c|c|c|c|c|c|}
\hline \multirow[t]{2}{*}{ ERP } & \multicolumn{2}{|c|}{$\begin{array}{l}\text { BRICUS ( } 1) \\
\text { BRIC }=50 \%, \text { US }=50 \%\end{array}$} & \multicolumn{2}{|c|}{$\begin{array}{l}\text { BRICUS }(2) \\
\text { BRIC }=40 \%, \text { US }=60 \%\end{array}$} & \multicolumn{2}{|c|}{$\begin{array}{l}\text { BRICUS }(3) \\
\text { BRIC }=25 \%, \text { US }=75 \%\end{array}$} \\
\hline & (Real) & (Nominal) & (Real) & (Nominal) & (Real) & (Nominal) \\
\hline Mean & 13.59 & 16.66 & 11.71 & 14.77 & 8.88 & 11.94 \\
\hline StDev & 27.46 & 27.27 & 23.94 & 23.75 & 19.25 & 19.04 \\
\hline ShR & 0.50 & 0.61 & 0.49 & 0.62 & 0.46 & 0.63 \\
\hline Skew & -0.02 & -0.01 & -0.07 & -0.06 & -0.19 & -0.20 \\
\hline Kurt & 0.08 & 0.07 & -0.05 & -0.06 & -0.06 & -0.05 \\
\hline
\end{tabular}

Notes: This table reports the values of the mean, standard deviation, Sharpe ratio, skewness, and kurtosis for the ERP of three different BRICUS portfolios. The 'Consumer Price Index for All Urban Consumers: All Items', which captures US inflation (source: U.S. Department of Labor: Bureau of Labor Statistics), is used to compute real quantities. Mean and standard deviation values are annualized and expressed in percentage points. All equity returns are computed from US\$-based TRIs (i.e. dividends are included). Data are quarterly and run from 1988:1Q to $2008: 2 Q$.

Table 5

Model versus data: Asset prices (BRICUS portfolios).

\begin{tabular}{lllllll}
\hline Model & “(1)” $\left[\hat{\theta}_{d, 1}^{(1)}, \hat{\theta}_{d, 2}^{(1)}, \hat{\theta}_{d, 3}^{(1)}\right]$ & $\begin{array}{l}\text { Data } \\
\text { BRICUS (1) }\end{array}$ & “(2)” $\left[\hat{\theta}_{d, 1}^{(2)}, \hat{\theta}_{d, 2}^{(2)}, \hat{\theta}_{d, 3}^{(2)}\right]$ & $\begin{array}{l}\text { DATA } \\
\text { BRICUS (2) }\end{array}$ & “(3)” $\left[\hat{\theta}_{d, 1}^{(3)}, \hat{\theta}_{d, 2}^{(3)}, \hat{\theta}_{d, 3}^{(3)}\right]$ & $\begin{array}{l}\text { DATA } \\
\text { BRICUS (3) }\end{array}$ \\
\hline$E\left(R^{m}-R_{f}\right)$ & 1.04 & 13.59 & 1.05 & 11.71 & 1.71 & 8.88 \\
$\sigma\left(R^{m}\right)$ & 5.00 & 27.46 & 5.04 & 23.94 & 7.38 & 19.25 \\
$S h R$ & 0.21 & 0.50 & 0.21 & 0.49 & 0.23 & 0.46 \\
\hline
\end{tabular}

Notes: This table reports the annualized equity risk premium, $E\left(R^{m}-R_{f}\right)$, the mean risk-free rate, $E\left(R_{f}\right)$, and the Sharpe ratio, ShR. All entries are obtained from repetitions of small-sample simulations. $\left[\hat{\theta}_{c, 1}, \hat{\theta}_{c, 2} ; \hat{\theta}_{c, 3}\right]$ and $\left[\hat{\theta}_{d, 1}^{i}, \hat{\theta}_{d, 2}^{i}, \hat{\theta}_{d, 3}^{i}\right]$ are estimated via the empirical scheme reported in the appendix (see entries in Table B.2). All the other parameters are calibrated as in Table 2. Data are quarterly and run from 1988:1Q to 2008:2Q.

of the long run risk model to explain the moments of BRICUS portfolios which are nevertheless still far from their empirical counterparts.

\section{Concluding remarks}

In this paper, we use the long-run risk approach to explain the ERP of emerging markets. Specifically, we focus on a portfolio composed of BRIC equity indices. We show that, even if we account for the empirically observed autoregressive structure of US consumption and BRIC dividends, the model can, at best, provide a partial explanation of the ERP in BRIC markets. Potentially, there are many other explanations for such a large equity premium as, for instance, alternative assumptions about preferences (e.g., prospect theory and narrow framing), rare economic disasters, incomplete markets or some kind of market imperfections. Moreover, we recognize that many important factors, that arguably have a role in explaining the observed differences across equity markets (as for instance, political uncertainty, country-specific law reforms or nationalizations), are still out of the picture in the proposed framework as well as in other consumption-based environments. It would be extremely interesting to build an advanced two-country model where the previously listed country-specific characteristics, in conjunction with investors' preferences, determine the cross-country differences in the equity premium. We leave this challenge for future research.

\section{Acknowledgments}

The authors acknowledge the helpful comments of Jonathan A. Batten (the editor), Christian Schlag, and an anonymous referee. 


\section{Appendix A. Data}

US Consumption Growth

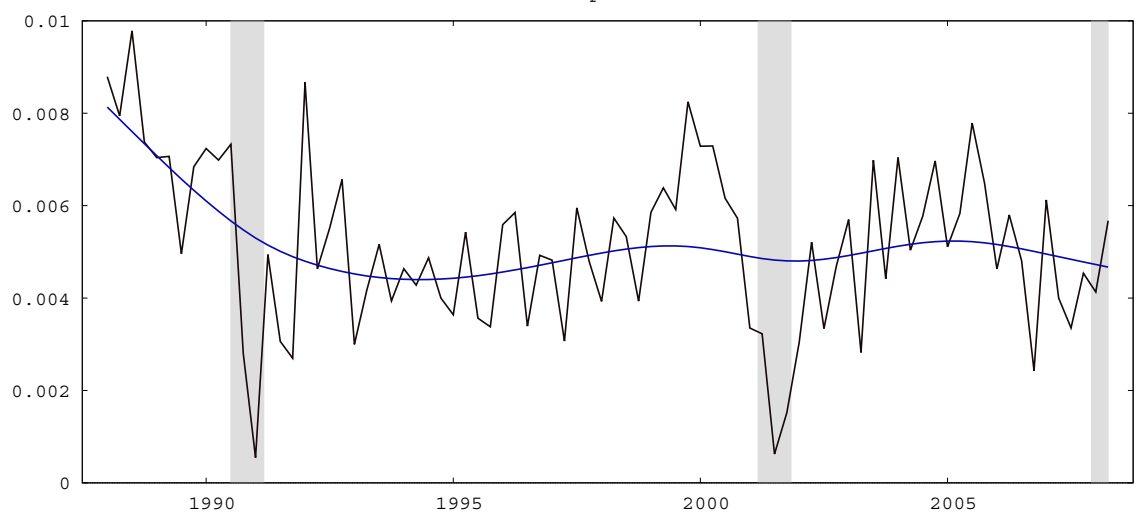

US Dividends Growth

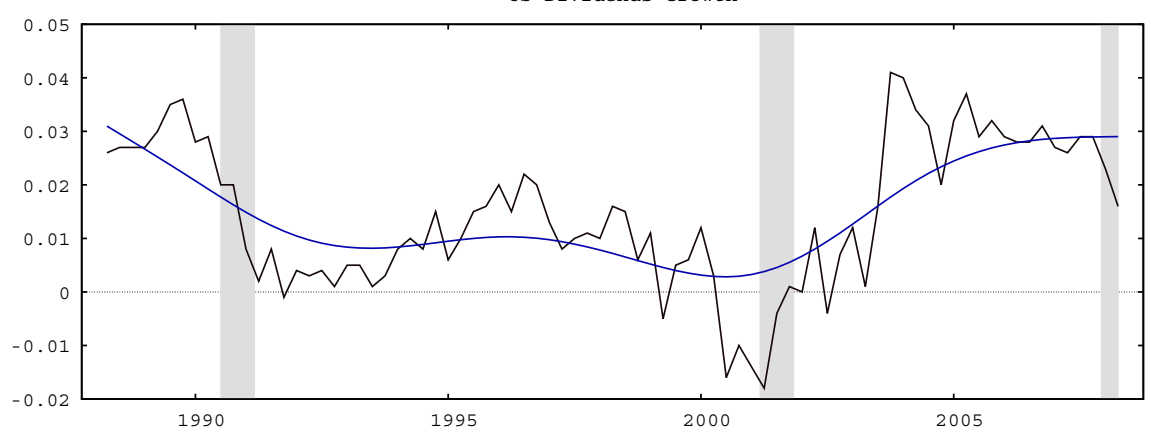

BRIC Dividends Growth

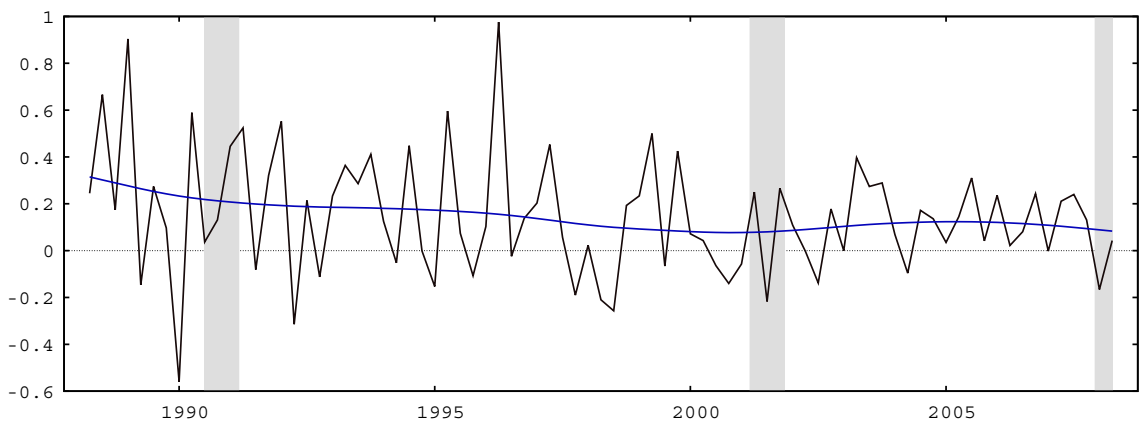

Fig. A.1. Consumption and dividend growth dynamics. Notes: Real per capita consumption is defined as the sum of personal consumption expenditures in non-durable goods (ID: A796RC0Q052SBEA) and services (ID: A797RC0Q052SBEA). Both series are from the Bureau of Economic Analysis. US real dividends are extracted from Robert Shiller's online database (http://www.econ.yale.edu/ shiller/data. $\mathrm{htm}$ ). US quarterly dividends are computed as averages of monthly figures. The dividend series for Brazil, China, India, and Russia are obtained as the difference between the MSCI TRI and the MSCI PI. Both MSCI TRIs and MSCI PIs are expressed in US\$ and downloaded from Datastream. BRIC dividends are deflated by using the 'US Consumer Price Index for All Urban Consumers: All Items'. Shaded areas denoted NBER-dated recessions. The trend line (blue line) is the smoothed estimate of the consumption and dividends growth (i.e. Hodrick-Prescott filtered series, $\lambda=1600$ ). Sample: 1988:1Q-2008:2Q. (For interpretation of the references to color in this figure legend, the reader is referred to the web version of this article.) 


\section{Appendix B. Estimation results}

\section{B.1. CASE I. US vs. BRIC portfolio}

We assume that both consumption and dividend growth rates are described by a third order autoregressive process. Formally,

$$
\begin{gathered}
\Delta c_{t}=k_{c}+\theta_{c, 1} \Delta c_{t-1}+\theta_{c, 2} \Delta c_{t-2}+\theta_{c, 3} \Delta c_{t-3}+\sigma_{c} \epsilon_{c} \\
\Delta d_{t}^{i}=k_{d}+\theta_{d, 1}^{i} \Delta d_{t-1}^{i}+\theta_{d, 2}^{i} \Delta c_{t-2}^{i}+\theta_{d, 3}^{i} \Delta d_{t-3}^{i}+\sigma_{d} \epsilon_{d}
\end{gathered}
$$

where $k_{c}, k_{d}$ are constants, $\epsilon_{c}, \epsilon_{d} \sim N(0,1), i=[U S, B R I C]$. Table B.1 displays the values of the estimated parameters for consumption and dividend growth.

\section{B.2. CASE II. The BRICUS portfolios}

As in (B.1), we assume that the growth rate of our BRICUS aggregated index is described by an AR(3) process. Estimated AR(3) parameters are reported in Table B.2.

Table B.1

Estimated AR(3) parameters: Consumption and dividend growth (US vs. BRIC).

\begin{tabular}{llll}
\hline Consumption growth & $\theta_{c, 1}$ & $\theta_{c, 2}$ & $\theta_{c, 3}$ \\
\hline$\Delta c_{t}$ & 0.206 & 0.095 & $0.251^{* *}$ \\
& {$[0.136]$} & {$[0.104]$} & {$[0.106]$} \\
Dividend growth & $\theta_{d, 1}$ & $\theta_{d, 2}$ & $\theta_{d, 3}$ \\
\hline$\Delta d_{t} \rightarrow$ US $(100 \%)$ & $0.532^{* * *}$ & 0.092 & 0.177 \\
$\Delta d_{t} \rightarrow$ BRIC $(100 \%)$ & {$[0.120]$} & {$[0.137]$} & {$[0.127]$} \\
& $-0.177^{*}$ & 0.014 & 0.130 \\
& {$[0.092]$} & {$[0.114]$} & {$[0.090]$} \\
\hline
\end{tabular}

Notes: This table reports the estimated autoregressive parameters for the US consumption growth rate $\left(\Delta c_{t}\right)$ and US and BRIC dividend growth rates $\left(\Delta d_{t}\right)$. Standard errors adjusted for heteroscedasticity and autocorrelation are reported in square brackets. ${ }^{* * *},{ }^{* *},{ }^{*}$ denote statistical significance at the $1 \%, 5 \%$ and $10 \%$ levels, respectively. The real US per-capita consumption is obtained from the Bureau of Economic Analysis (measured as non-durable goods plus services). BRIC dividends are computed as the difference between the MSCI Total Return Index (US\$) and the MSCI Price Index (US\$). US real dividends are extracted from Robert Shiller's online database ( $h t t p: / /$ www.econ.yale.edu/ shiller/data.htm). Sample: 1988:1Q-2008:2Q.

Table B.2

Estimated AR(3) parameters: Dividend growth (BRICUS).

\begin{tabular}{llll}
\hline Dividend growth & $\theta_{d, 1}$ & $\theta_{d, 2}$ & $\theta_{d, 3}$ \\
\hline Panel A: US $=50 \%$, BRIC $=50 \%$ & & & 0.133 \\
$\Delta d_{t} \rightarrow$ BRICUS $(1)$ & $-0.169^{*}$ & 0.023 & {$[0.090]$} \\
& {$[0.096]$} & {$[0.116]$} & 0.140 \\
Panel B: US $=60 \%$, BRIC $=40 \%$ & & & 0.031 \\
$\Delta d_{t} \rightarrow$ BRICUS(2) & $-0.163^{*}$ & {$[0.117]$} & $0.090]$ \\
& {$[0.096]$} & & $0.169^{*}$ \\
Panel C: US $=75 \%$, BRIC $=25 \%$ & & 0.051 & {$[0.088]$} \\
$\Delta d_{t} \rightarrow$ BRICUS(3) & -0.136 & {$[0.116]$} & \\
& {$[0.103]$} & & \\
\hline
\end{tabular}

Notes: This table reports the estimated autoregressive parameters for the dividend growth rate $\left(\Delta d_{t}\right)$ of three mixed US\$-based portfolios. Standard errors adjusted for heteroscedasticity and autocorrelation are reported in square brackets. ${ }^{* * *},{ }^{* *},{ }^{*}$ denote statistical significance at the $1 \%, 5 \%$ and $10 \%$ levels, respectively. BRIC dividends are computed as the difference between the MSCI Total Return Index (US\$) and the MSCI Price Index (US\$). US dividends are extracted from Robert Shiller's online database (http://www.econ.yale.edu/ shiller/data.htm). Sample: 1988:1Q-2008:2Q. 


\section{References}

Baele, L., Pungulescu, C., Horst, J.T., 2007. Model uncertainty, financial market integration and the home bias puzzle. J. Int. Money Financ. 26, 606-630.

Bansal, R., Yaron, A., 2004. Risks for the long run: a potential resolution of asset pricing puzzles. J. Financ. 59, 1481-1509.

Bekaert, G., Erb, C., Harvey, C., Viskanta, T., 1998. Distributional characteristics of emerging market returns and asset allocation. J. Portf. Manag. 24, 102-116.

Benartzi, S., Thaler, R.H., 1995. Myopic loss aversion and the equity premium puzzle. Q. J. Econ. 110, 73-92.

Brown, A.L., Kim, H., 2014. Do individuals have preferences used in macro-finance models? An experimental investigation. Manag. Sci. 60, 939-958.

Campbell, J.Y., Cochrane, J.H., 1999. By force of habit: a consumption-based explanation of aggregate stock market behavior. J. Polit. Econ. $107,205-251$

Diyarbakirlioglu, E., 2011. Foreign equity flows and the "size bias": evidence from an emerging stock market. Emerg. Mark. Rev. 12, 485-509.

Donadelli, M., 2013. Global integration and emerging stock market excess returns. Macroecon. Financ. Emerg. Mark. Econ. 6, 1-36.

Donadelli, M., Paradiso, A., 2014. Is there heterogeneity in financial integration dynamics? Evidence from country and industry emerging market equity indexes. J. Int. Financ. Mark. Inst. Money 32, 184-218.

Donadelli, M., Persha, L., 2014. Understanding emerging market equity risk premia: industries, governance and macroeconomic policy uncertainty. Res. Int. Bus. Financ. 30, 284-309.

Donadelli, M., Prosperi, L., 2012. The equity premium puzzle: pitfalls in estimating the coefficient of relative risk aversion. J. Appl. Financ. Bank. 2, 177-213

Edison, H.J., Warnock, F.E., 2004. U.S. investors' emerging market equity portfolios: a security-level analysis. Rev. Econ. Stat. 86, 691-704.

Epstein, L.G., Zin, S.E., 1989. Substitution, risk aversion, and the temporal behavior of consumption and asset returns: a theoretical framework. Econometrica 57, 937-969.

Grootveld, H., Salomons, R., 2003. The equity risk premium: emerging vs. developed markets. Emerg. Mark. Rev. 4, 121-144.

IFC, 1999. The IFC indexes: methodology, definitions and practices. World Bank Emerging Markets Data Base, July, Washington,D.C. Jagannathan, R., McGrattan, E.R., Scherbina, A., 2000. The declining U.S. equity premium. Fed. Reserv. Bank Minneap. Q. Rev. 24, 3-19.

Jahan-Parvar, M.R., Liu, X., Rothman, P., 2013. Equity returns and business cycles in small open economies. J. Money Credit Bank. 45, 1117-1146.

Lettau, M., Ludvigson, S., Wachter, J., 2006. The declining equity premium: what role does macroeconomic risk play? Rev. Financ. Stud. 21, 1653-1687.

Mehra, R., 2006. The Equity Premium in India. Oxford Companion to Economics in India.

Mehra, R., Prescott, E.C., 1985. The equity premium: a puzzle. J. Monet. Econ. 15, 145-161.

Mehra, R., Prescott, E.C., 2008. The equity premium: ABCs. In: Mehra, R. (Ed.), The Handbook of the Equity Risk Premium. Elsevier, Amsterdam, pp. 1-36.

Pancrazi, R., 2014. How beneficial was the Great Moderation after all? J. Econ. Dyn. Control. 46, 73-90.

Pancrazi, R., Vukotic, M., 2013. Technology Persistence and Monetary Policy. Working Paper.

Pukthuanthong, K., Roll, R., 2009. Global market integration: an alternative measure and its application. J. Financ. Econ. 94, $214-232$.

Shackman, J.D., 2006. The equity premium and market integration: evidence from international data. J. Int. Financ. Mark. Inst. Money $166,155-179$

Sorensen, B., Wu, Y.T., Yosha, O., Zhu, Y., 2007. Home bias and international risk sharing: twin puzzles separated at birth. J. Int. Money Financ. 26, 587-605.

Tretvoll, H., 2008. Home-bias in consumption and equities: can trade costs jointly explain both? Working Paper. 